\title{
Perspectives of Pharmacy University Students on Scientific Research in Comparison to Students from Other Health Science Disciplines
}

\author{
Syed Mohammed Basheeruddin Asdaq ${ }^{1}$, Mohammed Kanan Alshammari², Bassam Mohammed \\ Alanazi ${ }^{3}$, Ahmed Naif Alshammari ${ }^{4}$, Mishal Abdulrahman Alrumaih ${ }^{5}$, Mohd. Imran ${ }^{6}$, \\ Abdulhakeem S Alamri ${ }^{7,8}$, Majid Alhomrani ${ }^{7,8}$, Walaa F. Alsanie ${ }^{7,8}$, Nagaraja Sreeharsha ${ }^{9,10, *}$ \\ 'Department of Pharmacy Practice, College of Pharmacy, AlMaarefa University, Dariyah, Riyadh, SAUDI ARABIA. \\ 2Department of Pharmaceutical Care, Rafha Central Hospital, North Zone, Rafha, SAUDI ARABIA. \\ ${ }^{3}$ Department of Neuroscience, Tabuk Pharmaceuticals Manufacturing, Central Region, Riyadh, SAUDI ARABIA. \\ ${ }^{4}$ Department of Pharmaceutical Care, Aluawqilah Central Hospital, North Zone, Aluawqilah, SAUDI ARABIA. \\ ${ }^{5}$ Al-Dawaa Medical Services Company (DMSCO), Eastern Zone, Dammam, SAUDI ARABIA. \\ ${ }^{6}$ Department of Pharmaceutical Chemistry, Faculty of Pharmacy, Northern Border University, Rafha, SAUDI ARABIA. \\ ${ }^{7}$ Department of Clinical Laboratories Sciences, College of Applied Medical Sciences, Taif University, Taif, SAUDI ARABIA. \\ ${ }^{8}$ Centre of Biomedical Sciences Research (CBSR), Deanship of Scientific Research, Taif University, SAUDI ARABIA. \\ 'Department of Pharmaceutical Sciences, College of Clinical Pharmacy, King Faisal University, Al-Ahsa, SAUDI ARABIA. \\ ${ }^{10}$ Department of Pharmaceutics, Vidya Siri College of Pharmacy, Off Sarjapura Road, Bangalore, Karnataka, INDIA.
}

\begin{abstract}
Background: The value of scientific research should be instilled in students from the very beginning of their university education, to foster a creative attitude in the next generation. It is critical to promote a research culture using various technologies and strategies. Purpose: The purpose of this study was to assess students' perspectives towards scientific research and to learn more about the obstacles they confront in this area. Methods: Students at the Colleges of Medicine (COM), Pharmacy (COP), and Applied Sciences (CAS) were given a validated, pretested, and organized questionnaire (COA). Using the SPSS IBM 23 application, the data was examined utilizing descriptive statistics. Also, correlation statistics was done to determine the influence of perception, obstacles, and practices on each other. The statistical significance level was set at P\#0.05. Results: When compared to their COA counterparts (3.8/5), COM (4.3/5) and COP $(4.2 / 5)$ students had considerably higher average perception scores on the Likert response scale. The most significant barriers to undertaking research were a lack of time and research training. Both male and female students had a positive perception towards research. Female students, on the other hand, were more likely to engage in the practice. Positive correlation was noticed between perception and practice of scientific research. Higher level of obstacles influenced negatively on the practices of research among most of the University students. Conclusion: Although, college of Pharmacy and college of medicine students participate more regularly in scientific research, there is a need to orient them on the dissemination of their research outcomes. To foster a research environment and improve research practices among students, authorities and faculty members at AIMaarefa University should address and resolve these challenges.
\end{abstract}

Key words: AIMaarefa University, Obstacles, Practices, Perception, Scientific Research, University students.
Submission Date: 10-10-2021; Revision Date: 05-11-2021; Accepted Date: 16-12-2021

DOI: 10.5530/ijper.56.1.3 Correspondence: Dr. Syed Mohammed Basheeruddin Asdaq Professor, Department of Pharmacy Practice, College of Pharmacy, AlMaarefa University, Dariyah-13713, Riyadh, SAUDI ARABIA. E-mail: sasdaq@gmail.com

\section{INTRODUCTION}

In the realm of science and technology, research is seen as a crucial tool for growth and transformation. In most institutions around the world, it is a fundamental aspect of learning at the university level. ${ }^{1}$
Even at undergraduate training institutes, without adequate research orientation, the curriculum is regarded incomplete. From the start of their careers, research aids students in developing critical thinking, reasoning

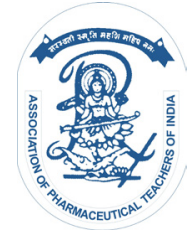

www.ijper.org 
abilities, and a positive mindset. ${ }^{2,3}$ It facilitates students' progression from beginner to advanced thinkers. ${ }^{4}$

In every country, health science education is an important component of university education. Hands-on training in research elements such as research proposal writing, comprehending research technique, statistical design upgrades, interpretive skills, and scientific writing should be instilled from the university level. ${ }^{5,6}$ A decrease in the number of research scientists among health care professionals ${ }^{7}$ needs immediate action to increase undergraduate research interest. Today's health university students will become tomorrow's health supply force warriors, such as physicians, pharmacists, and nurses. Early on, unfamiliarity with the research ${ }^{8}$ should not be used as a reason to avoid research output; rather, it can be mitigated by continual support and supervision from competent guides and advisors. Students' involvement in research not only helps them build analytical skills, but it also helps them gain admission to higher education programs such as residency programs and improves post-graduate output. ${ }^{9}$ Nevertheless, various studies have revealed that university students confront numerous challenges in their research endeavors. ${ }^{10}$

Among the health professions trained at Health Science University are physicians, pharmacists, nurses, emergency medical workers, anesthesia technologists, and respiratory therapists. It is vital to promote legitimate research efforts among all specialists in the health sciences to provide best medical care. Even though there have been numerous studies on the perceptions, barriers, and practices of research among medical students, ${ }^{10-13}$ we were unable to find a comprehensive study that determined the same parameters of research among undergraduate students in other health science programs such as pharmacy, nursing, and other applied health science programs, except for a study done by us a few years ago. ${ }^{14}$ However, a lot has changed at this institute since then. AlMaarefa College has been granted university status and has received accreditation from the National Center for Academic Accreditation and Assessment (NCAAA), a national accreditor. The rate of faculty publication has increased significantly at the university. However, in the research arena, it is necessary to understand the influence of these changes on the student community. As a result, the study used a cross-sectional study design to uncover the perceptions, barriers, and practices of scientific research among undergraduate students at AlMaarefa University in Riyadh, Saudi Arabia.

\section{MATERIALS AND METHODS} Subjects and methods

The current study was based on a cross-sectional survey of AlMaarefa University students in Riyadh. From March to May 2021, the research was carried out at the Colleges. The data was collected using a standardized questionnaire that had been pre-designed and tested. Participation in this study survey was fully voluntary, and the survey findings were kept completely confidential and anonymous, with no identifying information being collected. A consent form outlining the study's objective and requesting their participation was added to the beginning of the questionnaire. The Research Committee of AlMaarefa University in Riyadh granted the necessary clearance.

\section{Eligibility criteria}

This survey comprised students from AlMaarefa University who had completed at least four levels of studies in their respective programs and were Saudi Arabian residents. This survey did not include students who were enrolled for part-time programs of the University.

\section{Study design}

A cross-sectional comparative study design was used to conduct the current investigation. We chose crosssectional design since it is a time-limited study that must be finished in a short period of time. It is a comparative study since it requires a comparison of the College of Medicine cohort with the College of Pharmacy cohort and the College of Applied Science cohort. To answer research questions, the study used a questionnaire format. The questionnaire was developed after a thorough assessment of the literature and consultation with professionals in the field. Following validation, the questionnaire was put through a pilot study with a small sample size. The pre-test report was used to fine-tune the questionnaire.

\section{Data collection}

There were four sections to the questionnaire. The participants' age, gender, colleges/departments, study level, GPA, marital status, location, country, working status, and educational level of father and mother were all noted in the first section.

In the second section, students' perception toward research were assessed using questions. The responses to the questions were based on a Likert scale of 1 to $5(1=$ completely disagree, $2=$ disagree, $3=$ neutral, $4=$ agree, $5=$ completely agree). There were nine 
assertions in the perception portion, representing various facets of health science research. The mean is the average of the responses, and it represents the overall answer of each cohort.

Questions about the obstacles/barriers that restrict students from doing or engaging in health science research were also included in the survey questionnaire. The questionnaire's barrier items ( $n=14$ items) were formulated. Each barrier item was given a score based on the following criteria: 1 means absolutely disagree; 2 means disagree; 3 means neutral; 4 means agree; 5 means totally agree. The mean is the average of the responses, and it represents the overall answer of each cohort.

The next section includes 09 statements to help understand current research techniques across all cohorts. The first statement sets the pace for the entire of the statements. Those who said yes to any research practice were asked to respond to the remaining questions. At least four statements from this section were tallied, and the proportion of people who agreed with them was calculated.

\section{Statistical analysis}

The data was entered and analyzed using version 23 of the statistical program for social science (IBM SPSS Inc., Chicago, IL, USA). Frequencies and percentages were used to present the data. The data obtained were tested, analyzed, and compared based he students' perceptions, obstacles, and practices using analysis of variance (ANOVA) and the post-ANOVA test LSD for multiple comparisons. Correlation statistics was done to determine the impact of perception, obstacles, and practices on each other. The significance criteria were applied at a $P$-value of \#0.05 for all purposes.

\section{RESULTS}

\section{Demographic characteristics}

The demographic distribution of the study participants is shown in Table 1 . Most of them $(80 \%)$ were between the ages of 20 and 25, with a nearly equal ratio of male and female participants. Each of the colleges had about identical numbers of participants, with the College of Medicine having somewhat more. Almost $80 \%$ of the students who took part in the study had a GPA of 1.6 or higher on a scale of one to four. Most of the surveyors were single (85\%) and Saudi nationals $(75 \%)$. Furthermore, 88 percent of them were unemployed, and $67 \%$ were from a city background. In addition, $78 \%$ of the students had a father with a university education, and 68 percent had mothers who had completed collegiate degrees.

\begin{tabular}{|c|c|c|}
\hline Age & Frequency & Percentage \\
\hline $20-25$ years & 383 & 80 \\
\hline $26-30$ years & 95 & 20 \\
\hline \multicolumn{3}{|l|}{ Gender } \\
\hline Male & 240 & 50 \\
\hline female & 238 & 50 \\
\hline \multicolumn{3}{|l|}{ College } \\
\hline College of Medicine & 180 & 38 \\
\hline College of Pharmacy & 150 & 31 \\
\hline College of Applied science & 148 & 31 \\
\hline \multicolumn{3}{|l|}{ Study level } \\
\hline $5-8$ & 286 & 60 \\
\hline $9-11$ & 192 & 40 \\
\hline \multicolumn{3}{|l|}{ GPA } \\
\hline $0-1.5$ & 100 & 21 \\
\hline $1.6-3$ & 200 & 42 \\
\hline $3.1-4$ & 178 & 37 \\
\hline \multicolumn{3}{|l|}{ Marital Status } \\
\hline Married & 72 & 15 \\
\hline Single & 406 & 85 \\
\hline \multicolumn{3}{|l|}{ Location } \\
\hline Urban & 320 & 67 \\
\hline Rural & 158 & 33 \\
\hline \multicolumn{3}{|l|}{ Nationality } \\
\hline Saudi & 360 & 75 \\
\hline Non-Saudi & 118 & 25 \\
\hline \multicolumn{3}{|l|}{ Working } \\
\hline Working & 56 & 12 \\
\hline Not working & 422 & 88 \\
\hline \multicolumn{3}{|l|}{ Educational level of father } \\
\hline Not educated & 25 & 5 \\
\hline Primary school & 36 & 8 \\
\hline Secondary school & 42 & 9 \\
\hline College & 375 & 78 \\
\hline \multicolumn{3}{|l|}{ Educational level of mother } \\
\hline Not educated & 23 & 5 \\
\hline Primary school & 36 & 8 \\
\hline Secondary school & 93 & 19 \\
\hline College & 326 & 68 \\
\hline
\end{tabular}

\section{Perception score of students from different colleges}

On any of the items of the perception evaluation on scientific research, there was no significant difference between the three colleges. Most students agreed that research plays an important role in providing better health care to patients. For the item 'obligating research participation' for health science students, the greatest 
Table 2: Average perception score of different colleges.

\begin{tabular}{|c|c|c|c|c|}
\hline Perception items & $\begin{array}{l}\text { College of } \\
\text { Medicine }\end{array}$ & $\begin{array}{l}\text { College of } \\
\text { Pharmacy }\end{array}$ & $\begin{array}{c}\text { College of } \\
\text { Applied } \\
\text { Science }\end{array}$ & $P$ value \\
\hline Role of research in health science field is important & 4.24 & 4.6 & 3.78 & 0.54 \\
\hline Research helps us in providing better patients' health care & 4.5 & 4.3 & 3.95 & 0.45 \\
\hline $\begin{array}{l}\text { Research participation should be made compulsory to all } \\
\text { students of health subjects }\end{array}$ & 4.6 & 4.5 & 4.1 & 0.23 \\
\hline $\begin{array}{c}\text { Conducting research during their graduate study will have } \\
\text { positive impact on students }\end{array}$ & 4.5 & 4.3 & 4.2 & 0.12 \\
\hline $\begin{array}{c}\text { Research is one of the essential item for your selection to } \\
\text { higher studies. }\end{array}$ & 4.2 & 4.2 & 4.0 & 0.54 \\
\hline Research helps us to develop team work spirit & 4.3 & 4.2 & 4.1 & 0.44 \\
\hline Research could be part of long term career goal & 4.4 & 4.3 & 3.6 & 0.32 \\
\hline $\begin{array}{l}\text { Undertaking research will increase already overloaded } \\
\text { academic activities }\end{array}$ & 3.7 & 3.6 & 3.0 & 0.21 \\
\hline Research will not help in improvement of subject knowledge & 2.4 & 2.5 & 2.5 & 0.22 \\
\hline
\end{tabular}

\begin{tabular}{|c|c|c|c|c|}
\hline Perception items & $\begin{array}{c}\text { College of } \\
\text { Medicine }\end{array}$ & $\begin{array}{l}\text { College of } \\
\text { Pharmacy }\end{array}$ & $\begin{array}{c}\text { College of } \\
\text { Applied Science }\end{array}$ & $P$ value \\
\hline Inadequate facility for research & 3.45 & 3.2 & 3.1 & 0.64 \\
\hline Difficulty in obtaining a research supervisor & 2.53 & 2.38 & 3.5 & 0.047 \\
\hline Unavailability of the samples (or patients) & 3.52 & 3.22 & 3.45 & 0.21 \\
\hline Lack of devices/instruments & 4.0 & 2.5 & 2.2 & 0.12 \\
\hline Inadequate support by mentors/assistant & 2.5 & 2.4 & 4.0 & 0.06 \\
\hline Lack of rewarding and/or motivation & 2.6 & 2.6 & 4.0 & 0.44 \\
\hline Difficulty obtaining approval for the study & 3.8 & 3.7 & 3.6 & 0.33 \\
\hline Lack of research funding & 2.5 & 2.7 & 2.6 & 0.25 \\
\hline Lack of time to do research & 2.4 & 2.5 & 2.5 & 0.22 \\
\hline Poor accessibility to database & 3.4 & 2.5 & 2.2 & 0.04 \\
\hline Lack of research training & 3.2 & 3.6 & 3.4 & 0.30 \\
\hline Deficiency of self-motivation & 3.4 & 3.7 & 4.0 & 0.06 \\
\hline Absence of research culture & 2.5 & 2.1 & 2.5 & 0.34 \\
\hline Discouragement from other students & 2.2 & 2.1 & 3.5 & 0.05 \\
\hline
\end{tabular}

average of the college of medicine was identified. The importance of research in the health science field received the highest grade from students at the College of Pharmacy. Students from colleges of applied science gave the highest marks for the importance of research in making a beneficial impact in their professional lives. Students gave the lowest ratings to the last two negative items, showing that they are passionate about participating in scientific research activities.

\section{Obstacles for research}

Table 3 shows that there was a significant difference in the level of obstacles students from various colleges confront when conducting scientific research. Students in the college of applied science were dissatisfied with the procedure for obtaining research supervisors, and their ratings were significantly lower $(P=0.047)$ than those given by students at other colleges. Another difficulty addressed by college of medicine students as compared to college of applied science and college of pharmacy students is database accessibility. When data from other colleges was compared to college of medical ratings, the $P$ value was less than 0.05 . When compared to students of medicine and pharmacy, another barrier ( $P$ value $=0.05)$ encountered by students of applied sciences is discouragement from their classmates. 


\begin{tabular}{|c|c|c|c|c|c|c|c|c|}
\hline \multirow[t]{2}{*}{ Research participation } & \multirow[t]{2}{*}{ Response } & \multicolumn{2}{|c|}{$\begin{array}{l}\text { College of } \\
\text { Medicine }\end{array}$} & \multicolumn{2}{|c|}{$\begin{array}{l}\text { College of } \\
\text { Pharmacy }\end{array}$} & \multicolumn{2}{|c|}{$\begin{array}{l}\text { College of applied } \\
\text { Sciences }\end{array}$} & \multirow[t]{2}{*}{ P-value } \\
\hline & & $\begin{array}{c}3^{\text {rd }} \\
y-4^{\text {th }} y\end{array}$ & $>4^{\text {th }} y$ & $3^{\text {rd }} y-4^{\text {th }} y$ & $>4^{\text {th }} y$ & $3^{\text {rd }} y-4^{\text {th }} y$ & $>4^{\text {th }} y$ & \\
\hline \multirow[t]{2}{*}{ 1) Participation in any research } & Yes & $55 \%$ & $80 \%$ & $25 \%$ & $80 \%$ & $20 \%$ & $60 \%$ & \multirow[t]{2}{*}{0.000} \\
\hline & No & $45 \%$ & $20 \%$ & $75 \%$ & $20 \%$ & $80 \%$ & $40 \%$ & \\
\hline \multirow{2}{*}{$\begin{array}{l}\text { 2) Oral presentation in } \\
\text { conference }\end{array}$} & Yes & $10 \%$ & $30 \%$ & $15 \%$ & $40 \%$ & $5 \%$ & $30 \%$ & \multirow[t]{2}{*}{0.032} \\
\hline & No & $90 \%$ & $70 \%$ & $85 \%$ & $60 \%$ & $95 \%$ & $70 \%$ & \\
\hline \multirow{2}{*}{$\begin{array}{l}\text { 3) Poster presentation in } \\
\text { conference }\end{array}$} & Yes & $5 \%$ & $40 \%$ & $51 \%$ & $50 \%$ & $5 \%$ & $10 \%$ & \multirow[t]{2}{*}{0.021} \\
\hline & No & $95 \%$ & $60 \%$ & $95 \%$ & $50 \%$ & $95 \%$ & $90 \%$ & \\
\hline \multirow[t]{2}{*}{ 4) Published articles in journal } & Yes & $2 \%$ & $20 \%$ & $5 \%$ & $20 \%$ & $0 \%$ & $10 \%$ & \multirow[t]{2}{*}{0.018} \\
\hline & No & $98 \%$ & $80 \%$ & $95 \%$ & $80 \%$ & $100 \%$ & $90 \%$ & \\
\hline
\end{tabular}

\begin{tabular}{|c|c|c|c|c|c|c|}
\hline \multirow[t]{2}{*}{ Comparison of variables } & \multicolumn{2}{|c|}{ College of Medicine } & \multicolumn{2}{|c|}{ College of Pharmacy } & \multicolumn{2}{|c|}{ College of Applied Science } \\
\hline & Rho value & $p$-value & Rho value & $p$-value & Rho value & $p$-value \\
\hline Perception, obstacles & -0.362 & 0.031 & -0.312 & 0.041 & -0.323 & 0.029 \\
\hline Perception, practice & 0.876 & 0.032 & 0.896 & 0.023 & 0.875 & 0.032 \\
\hline Obstacles, practice & -0.532 & 0.043 & -0.321 & 0.041 & -0.543 & 0.021 \\
\hline
\end{tabular}

\section{Students' practice of scientific research}

Table 4 shows how students from three colleges conduct research. Each of the four items evaluated in this section differed significantly between colleges. Students at colleges of applied sciences and pharmacy are less likely to participate in research in their third and fourth years, but students in colleges of medicine have described some level of participation in research during this early stage of their studies. In both the college of medicine and the college of pharmacy, $80 \%$ of students in the fourth year agreed to participate in research. The differences between colleges were found to be statistically significant $(P=0.000)$.

Although a lower number of students from each of the three colleges participate in oral presentations at conferences, a significantly $(P$ value $=0.032)$ larger proportion of students from the College of Pharmacy have done so than students from the other colleges.

When compared to other colleges, the college of pharmacy had a significantly higher number of students presenting posters at conferences $(P$ value $=0.021)$.

Overall, the rate of publishing among all students is low; however, students in the colleges of medicine and pharmacy published significantly more $(P$ value $=0.018)$ than students in the colleges of applied sciences.

\section{Correlation between perception, obstacles, and practices of research}

Table 5 summarizes the relationships between the three areas. Perception and practices showed a positive correlation, but obstacles had a negative impact on students' practice and perception in all three colleges. The relationship was found to be significant.

\section{DISCUSSION}

The purpose of this study was to find out how students at AlMaarefa University in Riyadh, Saudi Arabia, perceive research, as well as the difficulties they face. When comparing students at Colleges of Medicine and Pharmacy to students at Colleges of Applied Sciences, the study found that students in Colleges of Medicine and Pharmacy have a higher interest in research.

The importance of research among health science students cannot be overstated. Instilling a positive mindset in students can lead to better research practices among future health care providers. In contrast to prior findings done in Saudi Arabia, students' perceptions of research are shifting in today's environment. ${ }^{15}$ Students in both the colleges of medicine and pharmacy recognize the value of research in the health sciences. The majority of the study's 478 participants (Table 1) were eager to 
participate in research. They think that research will aid them in learning better patient care, and they believe that research participation should be made mandatory during their academic careers. A substantially higher number of pupils disproved the myth that research will not aid in their knowledge advancement (Table 2). Our findings are consistent with those of $\mathrm{Nel} e t \mathrm{al}$. who found that the importance of research is valued by students in health science schools. ${ }^{16}$

The male and female students in our study reported considerable difficulties inhibiting research during their undergraduate studies, with the majority citing a lack of time and research training as main obstacles to research at AlMaarefa (Table 3). This finding could be explained by a shortened semester during the time of survey due to COVID-19 pandemic; however, to overcome this obstacle, regular training sessions are required. Lack of time for research among university students is a widespread complaint observed in other studies as well. ${ }^{16}$ Despite their enthusiasm in research, this is one of the factors that prevents individuals from participating in studies. Inadequate research facilities, difficulty obtaining a research supervisor, unavailability of samples (or patients), lack of devices/instruments, inadequate support by mentors/assistants, lack of rewarding and/or motivation, difficulty obtaining approval for the study, lack of research funding, poor database accessibility, lack of self-motivation, absence of research culture, and discouragement are some of the other barriers to participation in research that have been identified. On a Likert answer scale, the majority of these assertions obtained a 3 to 4 out of 5 rating. These factors must be addressed as soon as possible before they become a major threat (Table 3).

The majority of them agree on the value of research and would like to participate, as shown in Table 1, but difficulties at AlMaarefa University prohibit them from doing so. This is evidenced by the fact that students engage in a lesser percentage of research activities, and even when they do, they only participate in the basic stages. As a result, over half of students indicate that they conduct research, but only a small percentage of them communicate their findings orally or on a poster (Table 4). Even more surprisingly, just a small minority of researchers are willing to submit their research articles to journals for possible publication. When comparing students from the colleges of medicine and pharmacy to those from the colleges of applied sciences, the percentage of students who participated in research was significantly greater. College of Medicine and College of Pharmacy statistics suggest that research engagement increases progressively as student's progress to higher levels of study, however college of applied sciences data shows no change. The steady increase in research practice by students in the colleges of medicine and pharmacy is comparable to that described earlier by Vujaklija et al. ${ }^{17}$ who found an increase in research activity as junior students progressed to senior students. ${ }^{17}$ When comparing comments from colleges of medical and pharmacy, we find that involvement in research occurs earlier in colleges of medicine than in colleges of pharmacy.

There are several drawbacks to this study as well. Because those students who opted to participate may be better familiar with research, self-selection bias may have been a restriction factor in this study. However, due to the low refusal rate in this study and the inclusion of only senior students (level 5) with some research experience, this factor appeared to play little or no effect in the study outcomes. Furthermore, this study only included students from AlMaarefa University, and the sample size was small. Although the number of participants from each college is nearly identical, it is not proportional to the strength of the students in the college of medical and applied sciences, suggesting unequal sample size bias. As a result, this does not correctly represent a comparison of three colleges. For the findings of this study to be generalizable, future research will need to be conducted over a longer period of time with a bigger sample size.

\section{CONCLUSION}

Students' perceptions toward medical research were positive in both male and female students. Female students, on the other hand, were more likely to engage in the scientific research practice. College of medical students had a superior understanding and practice of research than college of pharmacy and applied science students. However, there is no substantial difference in research perception and practice between college of medical and college of pharmacy students. A variety of obstacles were discovered that prevented students from conducting research. To ensure an improvement in research activities among AlMaarefa university students, academic personnel and administrators must address and solve these hurdles.

\section{Recommendations}

At the end of our research, we recommend that more information about research be disseminated by organizing research orientations, such as a more 
active research day and a research culture campaign. Assess the obstacle on a regular basis, and teachers and management should make genuine attempts to eliminate

it. Teachers and students alike need to be motivated to conduct research. Teachers who are motivated will go out of their way to motivate their students. This will have a long-term and ever-encouraging effect on research in AlMaarefa University.

\section{Funding}

The author Walaa F. Alsanie supported by Taif University with number (TURSP-2020/53), Taif University, Taif, Saudi Arabia.

\section{ACKNOWLEDGEMENT}

Syed Mohammed Basheeruddin Asdaq, would like to thank AlMaarefa University, Riyadh, Saudi Arabia for extending support (TUMA-2021-1) to do this research.

\section{CONFLICT OF INTEREST}

The authors declare no conflict of interest.

\section{REFERENCES}

1. Castellanos YC, Ríos-González CM. The importance of scientific research in higher education. Medicina Universitaria. 2017 Jan 1;19(74):19-20.

2. Amin TT, Kaliyadan F, Al Qattan EA, Al Majed MH, Al Khanjaf HS, Mirza M. Knowledge, attitudes and barriers related to participation of medical students in research in three Arab Universities. Educ Med J. 2012;4(1). doi: 10.5959/ eimj.v4i1.7.

3. Khan H, Khawaja MR, Waheed A, Rauf MA, Fatmi Z. Knowledge and attitudes about health research amongst a group of Pakistani medical students. BMC Med Educ. 2006;6:54. doi: 10.1186/1472-6920-6-54, PMID 17081286.

4. [cited 15/3/17]Available from: http://serc.carleton.edu/introgeo/studentresearch/ Why.html at 8.42 pm GST.
5. Burgoyne LN, O'Flynn S, Boylan GB. Undergraduate medical research: the student perspective. Med Educ Online. 2010;15. doi: 10.3402/meo. v15i0.5212, PMID 20844608.

6. Shewan LG, Glatz JA, Bennett CC, Coats AJ. Contemporary (post-Wills) survey of the views of Australian medical researchers: importance of funding, infrastructure and motivators for a research career. Med J Aust. 2005;183(1112):606-11. doi: 10.5694/j.1326-5377.2005.tb00051.x, PMID 16336146.

7. Siemens DR, Punnen S, Wong J, Kanji N. A survey on the attitudes towards research in medical school. BMC Med Educ. 2010;10(1):4. doi: 10.1186/14726920-10-4, PMID 20096112.

8. Ávila MJ, Rodríguez-Restrepo A. The importance of research in undergraduate medical education. Medwave. 2014;14(10):e6032. doi: 10.5867/medwave.2014.10.6032, PMID 25587714.

9. Niessen AS, Meijer RR. On the use of broadened admission criteria in higher education. Perspectives on Psychological Science. 2017 May;12(3):436-48.

10. Dena KP, Suzanne AB, Michael WK. Student perceptions of the effectiveness of education in the responsible conduct of research. Scieng Ethics. 2006;12(3):571-82.

11. Lev EL, Kolassa J, Bakken LL. Faculty mentors' and students' perceptions of students' research self-efficacy. Nurse Educ Today. 2010;30(2):169-74. doi: 10.1016/j.nedt.2009.07.007. PMID 19682774.

12. Houlden RL, Raja JB, Collier CP, Clark AF, Waugh JM. Medical students' perceptions of an undergraduate research elective. Med Teach. 2004;26(7):659-61. doi: 10.1080/01421590400019542, PMID 15763861.

13. Noorelahi MM, Soubhanneyaz AA, Kasim KA. Perceptions, barriers, and practices of medical research among students at Taibah College of Medicine, Madinah, Saudi Arabia. Adv Med Educ Pract. 2015;6:479-85. doi: 10.2147/ AMEP.S83978, PMID 26185479.

14. Aldaihan F, Al-Anzi A, Al-Baz A, Shubt Y, Al-Mutairi S. Asdaq Smb, et al. Perceptions, Obstacles and Practices of research amongst students of AlMaarefa Colleges: A cross sectional comparative study. Int J Biol Pharm Allied Sci. 2018;7(6):976-90.

15. AlGhamdi KM, Moussa NA, Alessa DS, Alothimeen N, Al-Saud AS. Perceptions, attitudes and practices toward research among senior medical students. Saudi Pharm J. 2014;22(2, April):113-7. doi: 10.1016/j. jsps.2013.02.006, PMID 24648822.

16. Nel D, Burman RJ, Hoffman R, Randera-Rees S. The attitudes of medical students to research. S Afr Med J. 2013;104(1):33-6. doi: 10.7196/samj.7058. PMID 24388084.

17. Vujaklija A, Hren D, Sambunjak D, Vodopivec I, Ivanis A, Marusić A, et al. Can teaching research methodology influence students' attitude toward science? Cohort study and nonrandomized trial in a single medical school. J Investig Med. 2010;58(2):282-6. doi: 10.2310/JIM.0b013e3181cb42d9, PMID 20130460.

Cite this article: Asdaq SMB, Alamri A, Alhomrani M, Alsanie WF, Sreeharsha N. Perspectives of Pharmacy University Students on Scientific Research in Comparison to Students from other Health Science Disciplines. Indian $\mathrm{J}$ of Pharmaceutical Education and Research. 2022;56(1):17-23. 